\title{
Experts' Perspective on the Development of Experiential Marketing Strategy: Implementation Steps, Benefits, and Challenges
}

\author{
Ana-Maria Urdea (D) and Cristinel Petrișor Constantin * \\ Faculty of Economic Sciences and Business Administration, Transilvania University of Brașov, 500036 Brașov, \\ Romania; ana.urdea@unitbv.ro \\ * Correspondence: cristinel.constantin@unitbv.ro
}

check for updates

Citation: Urdea, Ana-Maria, and Cristinel Petrișor Constantin. 2021

Experts' Perspective on the

Development of Experiential

Marketing Strategy: Implementation Steps, Benefits, and Challenges.

Journal of Risk and Financial

Management 14: 502. https://

doi.org/10.3390/jrfm14100502

Academic Editor: Thanasis Stengos

Received: 6 August 2021

Accepted: 15 October 2021

Published: 19 October 202

Publisher's Note: MDPI stays neutral with regard to jurisdictional claims in published maps and institutional affiliations.

Copyright: (c) 2021 by the authors. Licensee MDPI, Basel, Switzerland. This article is an open access article distributed under the terms and conditions of the Creative Commons Attribution (CC BY) license (https:// creativecommons.org/licenses/by/ $4.0 /)$.

\begin{abstract}
Consumer needs change over time as a result of the fast-paced advancement in technology and the induction of the Internet, expansion that leads to a difficulty for brands to adapt their marketing promotion strategy and trying to remain innovative and effective at meeting their consumers' expectations. This research investigates what effect experiential marketing campaigns have on both customers' perception and business outcomes, aiming to develop a deeper understanding of experiential marketing, its challenges, and benefits, to understand customers' reactions to experiential touchpoints, to explore what type of technology increases experiential perceived value, and to envisage the evolution of experiential marketing strategy. To capture all the important facets of the research objectives, an exploratory survey based on the voices of 31 marketing experts from all around the world was applied. By identifying the key drivers of experiential marketing campaigns in a hybrid setting, the present study highlighted the important role that experiential marketing has as a communication strategy, offering additional insights to marketing specialists on the experiential marketing implementation steps. A theoretical framework of the steps needed to put into practice an experiential marketing strategy was proposed.
\end{abstract}

Keywords: experiential marketing; communication strategy; consumer perception; expert perspective

\section{Introduction}

In today's competitive market, marketing specialists develop new strategies and tactics to ensure customer loyalty and customer retention, concepts that integrate a brand's ability to gain repeat purchases. The concept of experiential marketing has been globally embraced as a guide to designing memorable experiences that succeed in satisfying target consumers (Chang 2020). Customers' behavior designates differentiation in consuming diverse products and creates positive or negative experiences, the reason why businesses create several experiences for their consumers as a way to encourage interaction with the products, developing various positive reactions or perceptions (Ihtiyar et al. 2019). Consumers have changed their needs, being more focused on experiences that are stimulating their sensations and emotions when they interact with a brand (Carù and Cova 2008). For this reason, the business-to-consumer (B2C) field was chosen to be approached in this study on the development of experiential marketing strategy. Accordingly, a new promotion strategy is required, one that enables consumers to experience marketing touchpoints around the landscape of consumption through personalized interaction design using new technology (Rather 2020), especially in times when information and digital technologies advance (Kuzior and Lobanova 2020).

The last few years have seen considerable growth in published scientific papers regarding the impact of experiential marketing strategy on consumers. Understanding customers' reactions to the involvement with a specific brand is one of the main objectives of marketing 
these days. Nevertheless, the complex field of experiential marketing implementation and evaluation strategies is not as well investigated as other paradigms in the vast field of marketing, as both theoretical or empirical research (Ihtiyar et al. 2019). Consequently, further research is needed based on the outcomes that experiential marketing touchpoints bring to both companies and consumers.

The purpose of the study is to identify the opinion of the worldwide marketing experts concerning the experiential marketing strategy, underlying the keys to a successful event built around the needs, preferences, and values of consumers. Therefore, in this study we investigate the essential elements of an experiential marketing event that immerses consumers in memorable experiences, seeking to answer the research question: What are the main steps of implementing an experiential marketing strategy with a positive impact on both customers' value and business outcomes? To answer this question, the following objectives have been established:

O1. Develop a deeper understanding of experiential marketing, its implementation steps, Key Performance Indicators (KPIs), and benefits;

O2. Explore the challenges of creating experiential marketing touchpoints;

O3. Prospect the current dynamics and future look of experiential marketing strategy.

Structuring the research on the aforementioned objectives, this study makes a significant theoretical and managerial contribution in the field of experiential marketing. From the multitude of techniques specific to qualitative marketing research, an exploratory study based on the voices of the experiential marketing experts was chosen. In order to do that, 31 qualitative surveys were conducted among experiential marketing specialists from different countries, aiming at a thorough comprehension of their opinions. The present research makes a valuable threefold contribution. First, it extends the existing theory on the experiential marketing domain by enhancing customer experience within the retail environment by using experiential marketing strategies. Second, it investigates new ways to conduct effective post-event evaluations by linking customer experiences to business outcomes. Third, it prospects the evolution of experiential marketing, preparing for the post-COVID-19 era. This article is structured as follows. First, we outline an experiential marketing strategy reviewing the literature based on the most relevant papers. Next, we present the exploratory research approach. Subsequently, the results of the research and discussion are presented, outlining managerial implications and the limitations of the study.

\section{Literature Review}

\subsection{Experiential Marketing as an Effective Communication Tool}

Marketing communication consists of essential activities performed by companies to inform, listen, and respond to the needs of the target customer (Rèklaitis and Pileliené 2019). In other words, the purpose of marketing communication policy is to promote the entire brand, besides placing the products on the market (Kusá and Urmínová 2020). An effective approach "in marketing communication is experiential marketing" strategy, an innovative method for increasing customers' holistic perception of their experience with a brand (Chaney et al. 2018), representing "the next logical stage" in consumer demands (Srinivasan and Srivastava 2010).

Experiential marketing was first conceptualized and discussed in one of the multiple studies of the author Schmitt (1999b), which has turned out to be an important communication strategy tool that has a positive effect on consumer behavior (Kailani and Narcisa 2015). Consumers' needs would objectify on marketing campaigns to heighten their senses, to enhance the sensory experience, and to stimulate their minds with interactive activities (Schmitt 1999b). Moreover, the authors Pine and Gilmore (1998) developed the concept of the experience economy that can be characterized by customer experiences as value-added elements and experiential events that engage the customer in a more personal way. Additionally, the author Schmitt (1999a) explained that the experiential element is an answer to the customer needs of a multisensory brand event. 
To enrich the brand experience, marketing specialists need to start to "strengthen the rights and values of the brand" (Österle et al. 2018 as cited in Yeh et al. 2019). For example, integrating a multisensory approach, experiential marketing is a communication tool that companies use to improve their marketing strategies with elements from sensory marketing that intensify consumers' experiences with a brand (Levy and Guterman 2021). According to Schmitt (1999a), experiential marketing is a technique that encourages consumers "to sense, feel, think, act and relate" with a brand. Cuellar et al. (2015) studied how businesses can exploit experiential marketing by strengthening customer relationships to increase their market share. Therefore, experiential marketing specialists should give attention to the customer consumption experience to obtain both rational and emotional involvement (Chang 2020).

Experiential marketing tactics develop a deeper connection based on personalized needs that each customer has through emotional impetus, transforming the act of consumption into a memorable experience (Gómez-Suárez and Yagüe 2021). Experiential marketing's main purpose is to create customer loyalty among the target market by stimulating emotions, designing positive experiences around a product (Nono and Yahya 2019). Furthermore, the most important thing in experiential marketing is to create communication touchpoints around the products or services through experience, this concept being considered a tool to encourage positive word-of-mouth (Masterman and Wood 2008). Consequently, an experiential marketing strategy is implemented more and more by marketers who want to build brand intimacy (Le et al. 2019), which denotes the "feeling of closeness" resulting from a positive customer brand connection (Almubarak et al. 2017). Furthermore, experiential marketing is one of the marketing strategies that has been applied extensively in different industries in the last few years.

A successful marketing event is marked by the power to spread feelings of entertainment, curiosity, and joyfulness among the customers (Khotimah et al. 2016). Nowadays, technology is one of the main features driving experiential marketing to positive results (Kumar 2014), and the reason why marketing specialists carefully select the tech tools that will be used to design an experiential touchpoint (Moise et al. 2012). Companies have already accepted that an experiential environment can be the main source of differentiation, being difficult to be imitated or replaced (Tsaur et al. 2007). For customers, one of the key benefits would be the chance to directly interact with a brand, to build meaningful connections around a memorable and unique moment that leads to a state of satisfaction (Kaufmann and Panni 2013). Marketing specialists' efforts focus on developing experiential marketing events that meet customers' expectations and desires on the "cognitive, affective, and social levels" (Tsai 2005). Moreover, the brand experiences need to coincide with the customers' needs, desires, and values (Battarbee and Koskinen 2005).

\subsection{Experiential Marketing in the Business-to-Consumer (B2C) Field}

Consumers are increasingly flexible in their decision-making process and have more choices than before, as a result of increasing growth in the number of offerings provided by numerous organizations, together with the expansion of available information and distribution channels (Wiedmann et al. 2018). This evolution affects the businesses negatively, making it increasingly hard to differentiate themselves in this dynamic market that puts customers' basic needs first. Therefore, to gain a competitive advantage, businesses are encouraged by both the market and their consumers, to implement experiences of interaction (Gentile et al. 2007). In addition, marketing specialists should apply multisensory marketing strategies to highlight the distinctive features of a specific brand, creating a strong identity and increasing customer revisit intention (Jeon et al. 2020).

Nowadays, consumers "take a longitudinal perspective" when evaluating their consumption experiences, having the impression that they have had experience with a brand even before the consumption process, a phenomenon that occurs from the actions of advertising campaigns, promotion strategies, and positive word-of-mouth (Maklan and Klaus 2011). A decision to purchase in B2C is more emotional than rational, a reason why compa- 
nies are putting big efforts on their marketing communication strategy, trying to include elements such as "influencers, pricing, merchandising tricks" (Rèklaitis and Pilelienè 2019). It has been shown that customers prefer to collect strong positive memories rather than objects (Mostafa and Kasamani 2021), hence, organizations are using experiential marketing to create a strong multisensory experience by understanding the change in customers' needs and expectations. After experiencing a marketing touchpoint, it is very likely to appear changes in customer behavior, analyzing the new perceptions of consumers being crucial for designing new experiential marketing campaigns (Aronne 2009).

The changing market has led to the new competitive strategy, experiential marketing (Schmitt and Zarantonello 2013) being one marketing communication tool that can be used to engage customers on an emotional and sensorial level (Nono and Yahya 2019), being a successful strategy in the experiential era (Yaz1c1 et al. 2017). The customers' impulse is the need to "experience gratification associated with a product as they have imagined it" in an authentic way (Yazic1 et al. 2017). The increasingly significant role of experiential marketing in brand evaluations encourages companies to overcome traditional marketing strategies in favor of developing deeper meaning in customer's perceptions with the help of experiential touchpoints (Cliffe and Motion 2005). The dynamics of the current global market have made brands develop sustainable marketing principles regarding a customer-centric mindset to develop a competitive advantage (Loureiro 2013). Trying to differentiate the business with only traditional tools from the marketing mix is no longer a competitive advantage that would produce a positive response from the target market, but implementing experiential marketing is believed to be the next competitive battleground (Öztürk 2015).

\subsection{Experiential Marketing Strategy Implementation}

Knowing how to improve the marketing strategy using experiential elements is of great importance for customers, especially in times when marketing strategies are evolving from a "functionality-focused into an experience-focused view" (Liu et al. 2020). Therefore, understanding customer changing expectations and preferences is critical for a company's long-term performance in the current competitive environment (Felix 2015). Experiential marketing builds long-term customer relationships by developing customer positive perceptions, creating memories, and encouraging interaction and product trial (Datta 2017).

Experiential marketing campaigns stimulate internal customer responses more holistically, facilitating affective and behavioral outcomes (Mainolfi and Marino 2020; GómezSuárez and Yagüe 2021). Accordingly, events that incorporate sensory, emotional, and social information create more vivid images that are then associated with the specific brand (Harmeling et al. 2017). Besides, experiential marketing approaches are known for creative tactics that include viral marketing, guerilla marketing, or buzzmarketing, which offer many opportunities for companies to differentiate, making people talk about them (Klepek 2014). Moreover, in response to consumers' needs, new technologies changed the way businesses market products or services to their customers, producing benefits, but also triggering concerns among consumers, such as information security and potential privacy risks aspects (Grewal et al. 2020). Related to the Internet of Things (IoT) (Nguyen and Simkin 2017), artificial intelligence (Verma et al. 2021), and different types of virtual reality (Alcañiz et al. 2019), these advanced technologies are exerting a huge impact on experiential marketing strategy, adapting to the consumer's personalized needs and wants (Rust 2020).

Implementing an experiential marketing strategy is crucial for affecting how experiences are perceived and evaluated by consumers (Larocca et al. 2020). Therefore, key performance indicators (KPIs) are essential for evaluating the success of an experiential marketing campaign and for helping companies achieve their objectives (Ginevičius and Rutkauskas 2012). Measuring the effect of a marketing campaign on consumers is a prominent challenge because, even though quantitative metrics are successful, it has not been demonstrated whether those metrics offer suitable proxies for evaluating the outcomes of 
an experiential marketing campaign (Gräve 2019). The key aspects of experiential marketing performance include customer mindset outcomes, customer behavior outcomes, product market performance outcomes, and financial outcomes (Katsikeas et al. 2016). Understanding how to improve customer satisfaction is essential for the future development of an organization because it represents the degree to which consumer expectations of a product are satisfied. This aspect signifies a reflection of the similarity between expectations and outcomes (Assaf and Magnini 2012) that has a positive effect on the performance and profitability of a company (Suchánek and Králová 2018).

\section{Materials and Methods}

To capture all the important facets, outcomes, or implications associated with the complex domain of experiential marketing, an exploratory study based on the voices of the experiential marketing experts was considered an adequate methodological option to carry out this research. These valuable insights are more difficult to detect through a conventional quantitative research approach that would provide statistical relevance and generalize the findings (Williams and Moser 2019). Therefore, rather than focusing on statistical results, the current approach provides opportunities to investigate the experiential marketing phenomenon and to gain valuable insights into experiential marketing implementation steps. Thus, a theoretical framework could be designed even if the sample is a small one, unrepresentative for a certain population (McEachern et al. 2021).

\subsection{Samples and Data Collection}

The data collection procedure of the current study consisted of an exploratory survey that captured the experts' views on the current development of experiential marketing capabilities. All experts had a leading role in planning or implementing experiential marketing strategies, being actively involved in the whole process of conceiving, planning, or execution. Respondents were asked to discuss the implementation steps of developing an experiential marketing strategy, to list the benefits and the challenges of creating experiential marketing touchpoints, and to argue what are the most efficient KPIs, and what is the future look of this strategy. The data were gathered by using a questionnaire that was prepared with the help of QuestionPro survey software. The questionnaire was designed based on common techniques, such as adding large answer fields, letting respondents be as specific as possible, and giving them the chance to describe different experiences in their own voice. A link was distributed to a list of 221 experiential marketing experts via the social media platform, LinkedIn, on the authors' profiles. All respondents have experience in experiential marketing, working in various industries, such as marketing services, event management, retailing, and others. After eliminating the data sets that contained incomplete or defective answers, a final sample of 31 respondents was obtained (mean age $=37$ years; gender $=64.5 \%$ male, 35.5\% female) over three months between January and March 2021. Table 1 contains the summary profiles of the informants, and Appendix A provides a more detailed overview.

Table 1. Experts' sample profiles.

\begin{tabular}{|c|c|c|c|}
\hline \multirow{8}{*}{ Country } & India & 9 & $29 \%$ \\
\hline & United States of America & 6 & $19.4 \%$ \\
\hline & Romania & 3 & $9.7 \%$ \\
\hline & Germany & 3 & $9.7 \%$ \\
\hline & Great Britain & 2 & $6.5 \%$ \\
\hline & Canada & 2 & $6.5 \%$ \\
\hline & Italy & 2 & $6.5 \%$ \\
\hline & Others & 4 & $12.9 \%$ \\
\hline \multirow{4}{*}{ Industry } & Marketing Services & 12 & $38.7 \%$ \\
\hline & Event Management & 7 & $22.5 \%$ \\
\hline & Retailing & 4 & $12.9 \%$ \\
\hline & Others & 8 & $25.8 \%$ \\
\hline
\end{tabular}


Table 1. Cont.

\begin{tabular}{cccc}
\hline & $<30$ & 3 & $9.7 \%$ \\
Age & $30-39$ & 18 & $58 \%$ \\
& $40-49$ & 9 & $29 \%$ \\
& $>49$ & 1 & $3.2 \%$ \\
\hline \multirow{2}{*}{ Gender } & Male & 20 & $64.5 \%$ \\
& Female & 11 & $35.5 \%$ \\
\hline
\end{tabular}

\subsection{Data Analysis}

Coding a frame of qualitative data is an essential aspect in the process of transforming the raw collected data into a communicative report (Linneberg and Korsgaard 2019). Moreover, the process of coding in qualitative research enables collected data to be "assembled, categorized, and thematically sorted", resulting in an organized scheme ready for "the construction of meaning" (Williams and Moser 2019). Since the survey was based on open-ended questions, producing free-form, informant-driven text, the interpretative data analysis technique was applied to the data sets. After establishing a code for the themes in the process of open coding, the second level of coding, axial coding, was applied, after which the connections between themes are analyzed, and categorized. Subsequently, the authors applied inter-coder reliability (ICR) of all survey responses to provide "consistency and transparency of the coding process" ( $\mathrm{O}^{\prime}$ Connor and Joffe 2020) by asking an external expert to ensure a credible interpretation of data by facilitating the "identification, development, and refinement of themes" (McEachern et al. 2021) to ensure a credible interpretation of data. The results were also compared with other findings in the literature to assure the study validity by using data triangulation.

\section{Results}

The main research problem addressed in this study is the opportunity for companies to design and perform experiential marketing strategies to increase both customers' value and business outcomes. The results are presented for each of the research objectives in the following subsections.

\subsection{Experiential Marketing Strategy: Implementation Steps, Key Performance Indicators (KPIs),} Benefits (O1)

Experiential marketing may include a variety of marketing activities toward immersing customers within a brand's products by attracting them in a multisensory journey. But for that to happen, marketing specialists need to undertake a range of experiential marketing implementations steps that were identified by the selected experts. These activities include concept development, promotional event management, brand activation, tech tool selection, financial management, and effective budget execution, and evaluation. As a result, all these key activities take the form of the type of events that promote a product or a service through direct contact with consumers. These events were mentioned in the answers, the most popular being the roadshows, in-store events, exhibitions, interactive trade show booths, or ride-and-drive events. Interestingly, finding the audience's interests and emotional buttons can predict if an experiential marketing campaign is effective. The experts stated that the success of the experience lies in the unique combination of the nature of the product, audience, market awareness, and the activities planned around the product. For launching a new product during an experiential marketing campaign it is crucial to deliver the experience on a multisensory level because it is engaging and enables customers to interact directly with a certain product or a brand. Therefore, consumers should be able to process the experiential touchpoints through all visual, auditory, and tactile modalities. One expert described a successful marketing experiential event as follows:

"A successful event occurred when we were able to successfully identify the target market and then learn about customers' overall needs and desires. From here, we crafted a campaign that would best touch the customers. We were 
successful in the fact that we exceeded our daily and annual numbers of how many end-consumers we wanted to reach. Additionally, we were successful in the number of them that continued to interact with the brand after the experience had been complete".

One way that an experiential marketing strategy is different from other marketing tools represents the brand's opportunity to engage in direct communication with their customers. Unlike traditional marketing, experiential marketing gives consumers a chance to experience a brand differently, in a way that might positively affect their attitudes and behaviors. One respondent revealed some basic elements that an experiential marketing campaign should include:

"Consumers processed the experiential touchpoints through visual-the activation was held in an environment they wanted, it was held inside of a mobile unit that was crafted to their liking, through auditory-as we had sales representatives there talking about the product-and finally, through take-home items, including samples of the product as well as prizes or give-a-ways".

Unsurprisingly, most of the touchpoints applied by the experts during different experiential events were well appreciated by consumers, who were excited and more engaged with the specific brand than ever. These tactics include stunts, product showcases, or creative guerilla marketing actions. The surprise was even bigger for them when new technologies were used to enhance the overall experience. The omnichannel approach across the mobile platform, marketing automation, artificial intelligence, virtual reality, augmented reality, holographic, and other digital platforms are only some of the tools that experts use to develop attendee communication before, during, and after the experiential marketing event.

As experts rightly point out, after every experiential marketing campaign, it is important to evaluate the results that are dictated by the return of investment (ROI) model with specific key performance indicators (KPI) in order to measure the success and, at the same time, to be able to improve and evolve in the future. All experts evaluated the results after each experiential marketing event, some of the KPIs used by the experts including brand health measurement, consumption curve evolution, digital analytics in terms of views, interactions, actions, hashtags, dwell time around branding, booth traffic, attendee scoring, but also physical KPIs such as the number of attendees, interactions, expression of the audience, level of engagement, and last, market share and additional sales generated. However, measuring the impact of experiences is a notorious challenge because impressions and social sharing values cannot tell exactly how deeply the experience has influenced the target audience.

Experiential marketing campaigns should become immersive communication platforms that appeal to today's consumers who value live and authentic content. There are many reasons why companies choose to implement experiential marketing touchpoints, providing remarkable moments for customers that produce a long-lasting effect is only one of them. Our research revealed more benefits that are classified based on their nomination by the informants, and the number of informants mentioning the specific motives. Investing in effective experiential marketing campaigns can bring many benefits that can coincide with the reasons why specialists used this strategy in the first place. Table 2 presents further benefits of experiential marketing implementation.

It is no surprise that customer experience is the main reason why experts implement experiential marketing touchpoints. This element brings many benefits for both consumers and companies, customer experience being the foundation for increased customer value that leads to increased sales. Therefore, the most important reason for implementing an experiential marketing strategy for a business is delivering a great customer experience that is the best competitive advantage a company can secure. The companies were positively affected by improved customer engagement and customer loyalty, increased market share, and higher revenue generated. Moreover, brand and product awareness drive a performance marketing strategy by creating a positive effect on customer satisfaction 
during an experiential touchpoint. As experts emphasized, intelligent use of technology and entertainment determine the brand positioning and product demonstration, allowing brands to interact with potential end-consumers and current end-consumers. Accordingly, the use of experiential marketing can strengthen the relationship between a brand and consumers, enhance brand awareness, create buzz, and encourage consumer conversations about a product that leads to positive word-of-mouth.

Table 2. Benefits of implementing experiential marketing strategy $(n=31)$.

\begin{tabular}{cccc}
\hline First Nomination & \multicolumn{3}{c}{ Second Nomination } \\
\hline Customer experience & 12 & Brand awareness & 5 \\
Customer loyalty & 8 & Brand identity & 3 \\
Brand awareness & 6 & Market penetration & 2 \\
Product awareness & 4 & Product demonstration & 1 \\
Customer engagement & 3 & Positive review & 1 \\
Brand positioning & 3 & Brand association & 1 \\
Product demonstration & 2 & & 1 \\
Brand perception & 1 & & \\
Product development & 1 & & \\
Market share & 1 & & \\
\hline
\end{tabular}

\subsection{Challenges of Creating Experiential Marketing Touchpoints (O2)}

While there are many benefits associated with this marketing approach, there are inevitably some challenges involving experiential marketing that needs to be overcome to better scale the experiential event. To retain its competitive edge, a leading brand needs to implement the trends in customer behavior, technology, and the right engagement at the right time. Considering the challenges that the experts are facing, the key aspect targets the current COVID-19 pandemic situation that makes consumers avoid certain experiences, and together with the restrictions that do not allow organizing live events, it creates challenges for marketers to interact with their target audience. Therefore, specialists try to find innovative ways to reach consumers in their homes with the help of digital tools and virtual platforms, as a sample member pointed out:

"With the pandemic, there will be a higher need for experiential marketing. First, the desire and need for experiential marketing will increase given the lack of personal interaction, customers want to go back to experience. Second, the experiential marketing activities will evolve and focus on more exclusive and intimate activities to minimize risks. And third, especially live experiential marketing will be all about feeling safe, so we as experts will need to learn how to address an additional challenge and make it to our advantage".

However, excluding the COVID-19 pandemic, conceiving of the "big experiential marketing idea" might be stimulating for marketers because it always has to be different and innovative, in order to provide "never-before-experience" and "cut-the-clutter" key factors. Another main challenge refers to providing a personalized experience to a large audience, a characteristic that will consume a lot of financial resources. Given resource constraints, many event organizers choose to share costs by partnering up with other brands and sponsors. These partners can often be cheaper than a full-time hire, freeing up your budget for other uses. In a more detailed manner, two respondents concede:

"In our case, the challenges involved the planning, security, and liability of handling a big in-presence event, looking after norms and local laws regarding young, teenagers' involvement. As well as all the logistics for events, press conferences and live presentations with the shows celebrities in both markets".

Another challenge concerns the "Insecurity about the data privacy when collecting data. Consumers are concerned mostly with giving out their information so that brands can interact with them regularly after the experience. They are 
hesitant to give out phone numbers and emails more than their physical address or mailing address or their social media accounts".

Real-life customer experience and interesting and engaging brand touchpoints raised from customer needs. It is extremely important for people to engage with brands, products, and services before making a purchase decision. Also, niche products can be best marketed through experiential marketing and not mass advertising. In short, marketers need to know the audience and define what they want to achieve, and make the activity unique and personalized, deploying the technology to its advantages. Some advice from an expert that marketing specialists should take into account is:

"Rigorous, methodical planning, huge attention to health, safety, and risk assessment and mitigation, contingency planning, agility and adaptability, resourcefulness, a solid team, creativity, and a sense of humor all are critical ingredients for success. Events appear to be easy, exceptional customer experiences are nothing short of magical, and are the outcome of huge professional work".

Experiential marketing has evolved consistent with the speed of technology over the last decade. As experts described, changes in how and where we consume content, continue to push brands to be more personal, placing a stronger focus on the digital marketing experience.

\subsection{Current Dynamics and Future Look of Experiential Marketing Strategy (O3)}

The COVID-19 pandemic has resulted in drastic changes to marketing, and especially to communication strategy, encouraging companies to reconsider their strategies, developing experiential marketing campaigns in order to maintain a sustainable revenue. Suddenly, consumers' perceptions of marketing have changed, with a growing number of brands understanding the need to use digital technology to create customer experiences. Nowadays, brands want real emotional experiences that connect the online and offline environments, building customer loyalty and retention.

Experts envision experiential marketing strategy implemented in large venues having people constantly interacting with digital tools that will let them experience the marketing touchpoints more deeply, with the opportunity to amplify the brand's experience and grow coverage. As follows, two experts consider that with accurate experiential marketing strategy and intelligent use of technology any brand can succeed:

"Experiential marketing is evolving more rapidly than ever before because of digital evolution and the COVID-19 pandemic. Augmented reality, virtual reality, mixed reality are the kind of technology which is yet to be explored to the fullest potential. I can be sure that technology, together with digital and experiential factors will revolutionize the marketing industry".

"I think technology will become a major part of any experiential event, whether this is virtual reality or just web-based meetings or events. VR is accepted by all ages, especially when it is something new, different, and wow factor. With the younger generations soon becoming the buying people, technology will be easier to implement as this is what they have grown up with".

Technological tools such as augmented, virtual, or mixed reality, artificial intelligence, holography, 3D printing, or Internet of Things systems encourage companies to create innovative and interactive consumer experiences. Moreover, incorporating interactive social media platforms into any experiential marketing event will grow the attendance, building awareness for people who cannot be physically at the event as well. As a result of physical and digital opportunities, hybrid events consisted of live events with limited attendee numbers, and simultaneous virtual events for a wider audience will be the solution post-COVID-19 pandemic, facts that can bring only opportunities for experiential companies.

Going beyond traditional marketing strategies means that brands have to go beyond traditional values. Fortunately, new technology has made improvements in experiential 
marketing strategy and contributed to customer satisfaction. A new digital tool that might help marketers collect more consumer data about participants is radiofrequency identification technology. Participants only need to slip RFID bracelets to attend a marketing event or make purchases, and marketers can access more data about each participant, including social accounts that can be monitored to see what is being said about the event. Social listening, in general, is an important way in which marketers can measure the impact of events, and brand lift surveys can also help measure this momentum.

\section{Discussion}

From the above results, we can appreciate that the objectives of the present research have been met. Valuable information has been obtained by exploring the theme of every objective concerning the implementation of experiential marketing strategy, the challenges that these campaigns face, and the future of experiential marketing strategy, together with the benefits for both customers and businesses have been revealed. These results helped us create a theoretical framework that contains the main steps for implementing an experiential marketing strategy, as a synthesis of the answers obtained from the exploratory research investigating the opinion of experts (Figure 1).

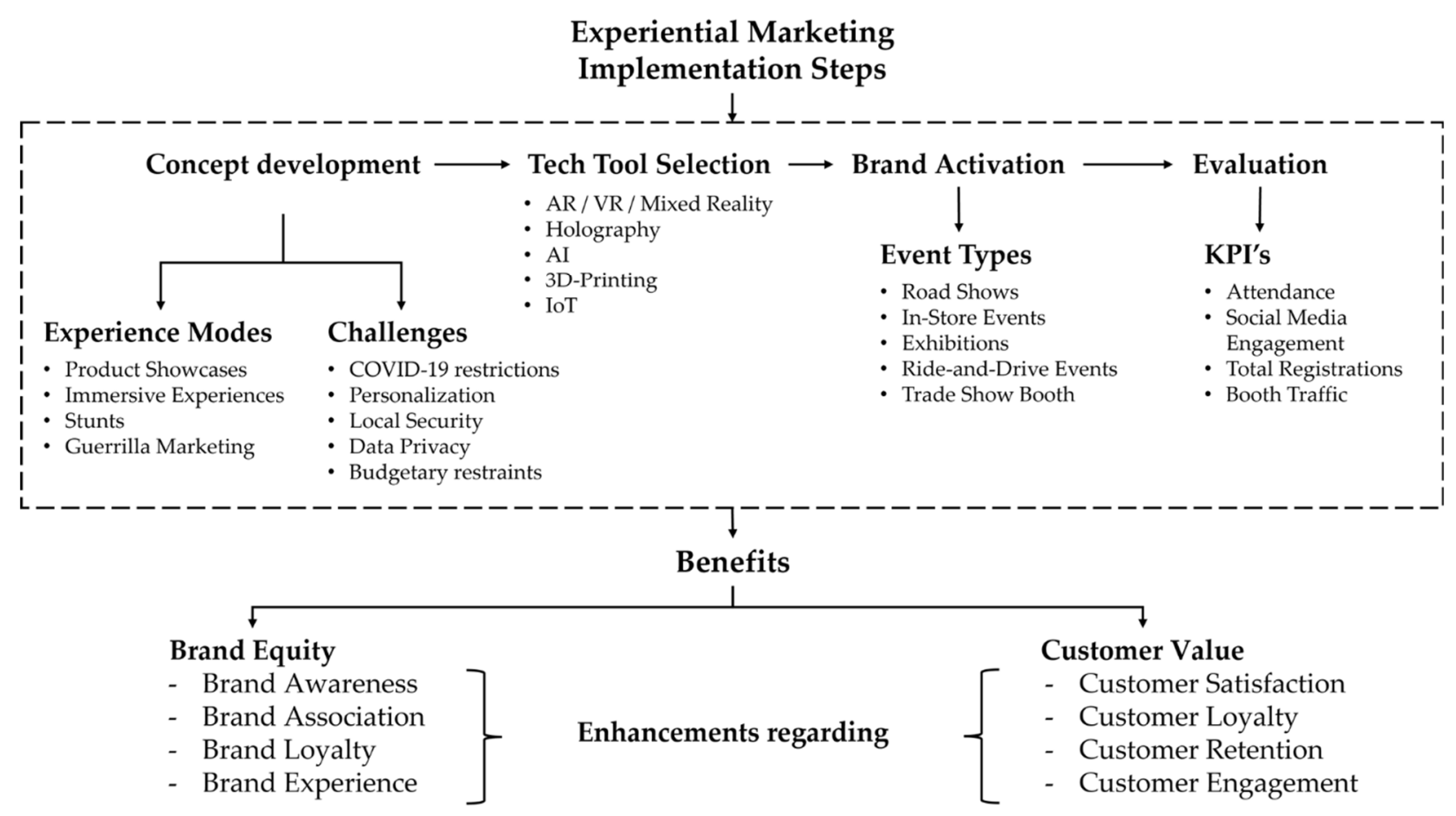

Figure 1. A comprehensive view of experiential marketing implementation steps.

The first step of developing the experiential marketing strategy is concept development, which includes different experience modes that attract customer attention and build an experiential environment. Sustaining the literature findings, the impact of constantly changing consumer behavior resulted in a new approach to the vast marketing area (Kailani and Narcisa 2015), one that provides valuable insights into creating memorable brand experiences, being essential for brand-differentiating and brand positioning in the current market environment. Customers nowadays expect the unexpected, and marketing experts exceed them by using touchpoints represented by stunts, displaying the products with innovative product showcases, and designing immersive customer experiences. These findings are in line with the attempt of Klepek (2014) to discover the tools that specialists should use to undertake effective marketing communication.

While developing the concept, the sample members focused on what challenges might be overcome. With the COVID-19 restrictions changing overnight, experts need to be 
constantly updated about the ones about public gatherings, healthy behaviors promotion to reduce the spread, or maintaining healthy environments for customers. Furthermore, there are some shifts in consumer behavior during the pandemic, that make experts wonder if these changes in behavior will also last after the pandemic subsides, or they will remain as new habits that consumers embrace. Apart from pandemic challenges, as mentioned in the current literature review, the authors Grewal et al. (2020) suggested that information security and privacy risks are triggered by the new technology adoption. Accordingly, experts' opinions include the action of configuring a security policy for a marketing event is another provocation for marketing specialists who need to ensure the safety of the customers, being one of the first components that should be considered. Moreover, customers are becoming concerned about protecting their data, making it difficult for the organizers to collect consumer data that would help meet their demands. However, many marketing experts plan to protect consumer data, trying to find other methods to satisfy personalized consumers' needs.

The second step of experiential marketing strategy development refers to a selection of tech tools that might enhance communication with the customers, resulting in higher customer engagement. Experts speculate on how the marketing strategies will change after the coronavirus pandemic, considering the digital competencies and technology tools crucial regarding the current communication policy. Digitalization is driven by fast technological progress and the desire for increased comfort and safety. Even if it is expected that the physical events will take place pretty soon, experts stated that hybrid events should be also implemented after the elimination of restrictions that were imposed in the pandemic because the virtual platforms can make the brand much visible for numerous customers. These results based on experts' perspectives are in line with other findings in the literature which asserts that experiential campaigns should involve interactive and engaging elements (Moise et al. 2012) through animations, product testing, holograms, augmented reality shopping apps, VR-based games, and other interactive digital tools. By developing and maintaining a brand that reaches out in a meaningful way to their audience, organizations can remain profitable while providing memorable customer experiences.

The third step of this strategy refers to brand activation that is based on experiential events that aim to engage with consumers, building awareness for a specific brand that can be materialized through many event types, such as roadshows, in-store events, exhibitions, ride-and-drive events, or trade show booths. The purpose of these marketing strategies is to engage key customers in a well-planned experiential marketing event that drives many benefits for brands. Nevertheless, post-event evaluation as the last step has a crucial role in outgrowing the competition, having the ability to evaluate what impact the event had on consumers' perception and to optimize any future planning process. Marketing specialists have to establish and measure KPIs for experiential marketing campaigns, selecting the variety of tools that can measure the effectiveness of an experiential marketing event. In comparison with the results of the indicators enumerated in the literature review such as customer mindset and behavior outcomes, product market performance, and financial outcomes (Katsikeas et al. 2016), experts found the attendance number, consumer activities, reactions on social media, and the contribution to create sales opportunities as best suited for the performance evaluation of an experiential marketing campaign.

\section{Conclusions}

Experiential marketing has proven to be an effective strategy, which uses several modes and techniques to create memorable experiences. This marketing strategy has a significant impact on consumer perception, bringing many advantages for both consumers and companies. Experts outlined the key brand benefits that include brand equity tenets, such as brand awareness, brand association, brand experience, and brand loyalty. Leveraging the power of positive brand equity, companies can sustain market share and increase customer value. Even if many of the benefits coincide with the results of the study of author Datta (2017), changing the mind of dissatisfied customers, verifying the target audience, 
and establishing relevance are aspects that might help companies have the desired impact and results. The perception of consumers, their buying decisions, and their loyalty depend greatly on the direct interactions with the offerings of a brand. Therefore, as was suggested in the current study and by authors Liu et al. in their recent research as well (Liu et al. 2020), marketing specialists should design a customer journey map with a focus on maximizing the experiential customer touchpoints, ensuring value proposition engagement with the customers.

Given all these considerations, the answer to the research question is that an experiential marketing strategy could offer benefits for both customers' value and business outcomes. The present research uncovers deeper insights into all the changes in the experiential marketing implementation, as a result of the advancement of its role in persuading consumers' journey perception, thereby this paper reveals a useful contribution to both marketing and management literature. Findings reveal planning steps of an effective experiential marketing strategy, event types based on several experiential modes and tech tools, most important key performance indicators, and benefits of customers and brands. This theoretical framework could contribute to the development of marketing theory, being of help for academia. We hope that these results could also help companies and marketing specialists to design and implement insightful experiences for consumers, guiding them to a better understanding of how to enhance experiential value perceptions.

This study has several limitations. First, given the qualitative nature of the research, the sample considered in this study is not statistically representative of a population, but it is sufficient to understand the depth of the current topic. Nevertheless, we would consider a larger sample for a future qualitative study. At the same time, because we focused only on the experts' perspectives, the future research direction will identify the perspective of consumers. Second, conducting quantitative research is suggested as well, for quantifying the opinions of both experts and consumers regarding their perspective on experiential marketing strategies to ensure a representative study of the researched population. Finally, focus group sessions are proposed for future research for exploring prospects for the development of experiential marketing in consumers' views.

Author Contributions: Conceptualization, A.-M.U. and C.P.C.; methodology, A.-M.U. and C.P.C.; writing-review and editing, A.-M.U. and C.P.C.; supervision, A.-M.U. and C.P.C. All authors have read and agreed to the published version of the manuscript.

Funding: This research received no external funding.

Institutional Review Board Statement: Not applicable.

Informed Consent Statement: Informed consent was obtained from all subjects involved in the study.

Data Availability Statement: Data sharing is not applicable to this article.

Acknowledgments: The authors would like to express their sincere gratitude to the editor.

Conflicts of Interest: The authors declare no conflict of interest.

Appendix A

Table A1. Experts of Qualitative Survey.

\begin{tabular}{cccccc}
\hline $\mathbf{R}$ & Occupation & Age & Gender & Industry Field & Country \\
\hline 1 & Digital and Experiential Marketing Specialist & 34 & $\mathrm{M}$ & Retailing & Canada \\
2 & Experiential Marketing Strategist & 34 & $\mathrm{~F}$ & Utilities & Germany \\
3 & Senior Experiential Marketing Events Specialist & 46 & $\mathrm{M}$ & Video Games & USA \\
4 & Tourism and Experiential Marketing Specialist & 25 & $\mathrm{M}$ & Marketing Services & Italy \\
5 & Experiential Marketer & 37 & $\mathrm{M}$ & Event Management & India \\
6 & Events and Experiential Marketing Specialist & 36 & $\mathrm{M}$ & Event Management & USA \\
7 & Experiential Marketing and Branding Specialist & 42 & $\mathrm{M}$ & Marketing Services & USA \\
\hline
\end{tabular}


Table A1. Cont.

\begin{tabular}{|c|c|c|c|c|c|}
\hline $\mathbf{R}$ & Occupation & Age & Gender & Industry Field & Country \\
\hline 8 & Marketing Consultant & 34 & $\mathrm{~F}$ & Marketing Services & India \\
\hline 9 & Marketing consultant & 53 & M & Event Management & USA \\
\hline 10 & Experiential Engagement Specialist & 37 & M & Media & UAE \\
\hline 11 & Senior Manager & 46 & M & Automotive & Romania \\
\hline 12 & Marketer and project management professional & 41 & $\mathrm{~F}$ & Marketing Services & UK \\
\hline 12 & New Business and PR & 34 & M & Marketing Services & Mexico \\
\hline 14 & Experiential marketing manager & 45 & M & Event Management & India \\
\hline 15 & Experiential Marketing Professional & 30 & M & Marketing Services & India \\
\hline 16 & Event Marketing Manager & 33 & $\mathrm{~F}$ & Retailing & Russia \\
\hline 17 & Marketing Manager & 27 & $\mathrm{~F}$ & Marketing Services & India \\
\hline 18 & National Account Executive & 30 & M & Marketing Services & USA \\
\hline 19 & Experiential Marketing Specialist & 26 & $\mathrm{~F}$ & Event Management & UK \\
\hline 20 & Experiential Marketing Manager & 33 & $\mathrm{~F}$ & Marketing Services & USA \\
\hline 21 & Marketing consultant & 47 & M & Event Management & India \\
\hline 22 & Experiential marketing specialist & 33 & M & Communication & Canada \\
\hline 23 & Client service lead & 34 & M & Marketing Services & Ireland \\
\hline 24 & Head of PR and Communication & 47 & $\mathrm{~F}$ & Retailing & Romania \\
\hline 25 & Marketing professional & 41 & M & Marketing Services & India \\
\hline 26 & Event Manager-Experiential Events & 47 & $\mathrm{M}$ & Event Management & India \\
\hline 27 & Experiential Marketing Manager & 39 & $\mathrm{~F}$ & Marketing Services & Italy \\
\hline 28 & Marketing Professional & 39 & $\mathrm{~F}$ & Retailing & Romania \\
\hline 29 & Experiential Marketing professional & 36 & M & Pharmaceuticals & India \\
\hline 30 & Creative Director & 31 & M & Media & Germany \\
\hline 31 & Experiential Marketing Specialist & 33 & $\mathrm{~F}$ & Automotive & Germany \\
\hline
\end{tabular}

\section{References}

Alcañiz, Mariano, Enrique Bigné, and Jaime Guixeres. 2019. Virtual Reality in Marketing: A Framework, Review, and Research Agenda. Frontiers in Psychology 10: 1530. [CrossRef]

Almubarak, Alanoud F., Simon J. Pervan, and Lester W. Johnson. 2017. A conceptual analysis of brand intimacy on social media platforms. Journal of Strategic Marketing 26: 463-78. [CrossRef]

Aronne, Lobo de Vasconcelos, ed. 2009. The Impact of Experiential Marketing on the Customer's Perception of a Brand's Essence. Paper presented at the XXXIII Encontro da ANPAD, São Paulo, Brazil, September 19-23.

Assaf, A. George, and Vincent Magnini. 2012. Accounting for customer satisfaction in measuring hotel efficiency: Evidence from the US hotel industry. International Journal of Hospitality Management 31: 642-47. [CrossRef]

Battarbee, Katja, and Ilpo Koskinen. 2005. Co-experience: User experience as interaction. CoDesign 1: 5-18. [CrossRef]

Carù, Antonella, and Bernard Cova. 2008. Small versus big stories in framing consumption experiences. Qualitative Market Research: An International Journal 11: 166-76. [CrossRef]

Chaney, Damien, Renaud Lunardo, and Rémi Mencarelli. 2018. Consumption experience: Past, present and future. Qualitative Market Research: An International Journal 21: 402-20. [CrossRef]

Chang, Wen-Jung. 2020. Experiential marketing, brand image and brand loyalty: A case study of Starbucks. British Food Journal 123: 209-23. [CrossRef]

Cliffe, Simon J., and Judy Motion. 2005. Building contemporary brands: A sponsorship-based strategy. Journal of Business Research 58: 1068-77. [CrossRef]

Cuellar, Steven S., Robert C. Eyler, and Rich Fanti. 2015. Experiential Marketing and Long-Term Sales. Journal of Travel E Tourism Marketing 32: 534-53.

Datta, Veto. 2017. A conceptual study on experiential marketing: Importance, strategic issues and its impact. International Journal of Research-GRANTHAALAYAH 5: 26-30. [CrossRef]

Felix, Egboro. 2015. Marketing Challenges of Satisfying Consumers Changing Expectations and Preferences in a Competitive Market. International Journal of Marketing Studies 7: 41. [CrossRef]

Gentile, Chiara, Nicola Spiller, and Giuliano Noci. 2007. How to Sustain the Customer Experience. European Management Journal 25: 395-410. [CrossRef]

Ginevičius, Romualdas, and Aleksandras Vytautas Rutkauskas, eds. 2012. The 7th International Scientific Conference "Business and Management 2012". Vilnius: Vilnius Gediminas Technical University Publishing House Technika.

Gómez-Suárez, Mónica, and María Jesús Yagüe. 2021. Making Sense from Experience: How a Sustainable Multi-Sensory Event Spurs Word-of-Mouth Recommendation of a Destination Brand. Sustainability 13: 5873. [CrossRef] 
Gräve, Jan-Frederik. 2019. What KPIs Are Key? Evaluating Performance Metrics for Social Media Influencers. Social Media + Society 5: 205630511986547. [CrossRef]

Grewal, Dhruv, John Hulland, Praveen K. Kopalle, and Elena Karahanna. 2020. The future of technology and marketing: A multidisciplinary perspective. Journal of the Academy of Marketing Science 48: 1-8. [CrossRef]

Harmeling, Colleen M., Jordan W. Moffett, Mark J. Arnold, and Brad D. Carlson. 2017. Toward a theory of customer engagement marketing. Journal of the Academy of Marketing Science 45: 312-35. [CrossRef]

Ihtiyar, Ali, Mehmet Barut, and Hatice Gulsah Ihtiyar. 2019. Experiential marketing, social judgements, and customer shopping experience in emerging markets. Asia Pacific Journal of Marketing and Logistics 31: 499-515. [CrossRef]

Jeon, Hyeon Mo, Se Ran Yoo, and Seon Hee Kim. 2020. The Relationships among Experience, Delight, and Recollection for Revisit Intention in Chocolate Exposition. Sustainability 12: 8644. [CrossRef]

Kailani, Camelia, and Ciobotar Narcisa, eds. 2015. Experiential Marketing: An Efficient Tool to Leverage Marketing Communication Impact on Consumer Behaviour. In International Conference on Marketing and Business Development. Bucharest: The Bucharest University of Economic Studies.

Katsikeas, Constantine S., Neil A. Morgan, Leonidas C. Leonidou, and G. Tomas M. Hult. 2016. Assessing Performance Outcomes in Marketing. Journal of Marketing 80: 1-20. [CrossRef]

Kaufmann, Hans-Ruediger, and Mohammad Fateh Ali Khan Panni. 2013. Customer-Centric Marketing Strategies. Hershey: IGI Global.

Khotimah, Khusnul, Diana Sari, and Umi Kaltum. 2016. Event Marketing and Experiential Marketing towards the Formation of Net Marketing Contribution Margin (NMCM) (Study at PT. Garuda Indonesia, TBK). Procedia-Social and Behavioral Sciences 219: 431-39. [CrossRef]

Klepek, Martin. 2014. Guerilla Marketing Concept and Further Research Possibilities. Opava: Silesian University in Opava, School of Business Administration in Karvina, pp. 79-87.

Kumar, Prarthana. 2014. Multisensory Marketing: Creating Sustainability Perspective in Various Sectors. Asia-Pacific Journal of Management Research and Innovation 10: 89-95. [CrossRef]

Kusá, Alena, and Marianna Urmínová. 2020. Communication as a Part of Identity of Sustainable Subjects in Fashion. Journal of Risk and Financial Management 13: 305. [CrossRef]

Kuzior, Aleksandra, and Alla Lobanova. 2020. Tools of Information and Communication Technologies in Ecological Marketing under Conditions of Sustainable Development in Industrial Regions (Through Examples of Poland and Ukraine). Journal of Risk and Financial Management 13: 238. [CrossRef]

Larocca, M. T. Grimaldi, Rodrigo Ladeira, Aurio L. L. Da Silva, and Ricardo C. Mello. 2020. Experience marketing: A study of the conceptual aspects. Cadernos EBAPE.BR 18: 781-93.

Le, Dung, Noel Scott, and Gui Lohmann. 2019. Applying experiential marketing in selling tourism dreams. Journal of Travel E Tourism Marketing 36: 220-35.

Levy, Shalom, and Hanna Gendel Guterman. 2021. Twofold impact of experiential marketing: Manufacturer brand and hosting retailer. EuroMed Journal of Business 16: 345-60. [CrossRef]

Linneberg, Mai Skjott, and Steffen Korsgaard. 2019. Coding qualitative data: A synthesis guiding the novice. Qualitative Research Journal 19: 259-70. [CrossRef]

Liu, Hongshen, Yuying Fu, and Hao He. 2020. The Mechanism of the Effects of Experiential Marketing on Urban Consumers' Well-Being. Complexity 2020: 8813906. [CrossRef]

Loureiro, Sandra Maria Correia. 2013. Consumer-Brand Relationship. In Customer-Centric Marketing Strategies. Edited by HansRuediger Kaufmann and Mohammad Fateh Ali Khan Panni. Hershey: IGI Global, pp. 414-34.

Mainolfi, Giada, and Vittoria Marino. 2020. Destination beliefs, event satisfaction and post-visit product receptivity in event marketing. Results from a tourism experience. Journal of Business Research 116: 699-710. [CrossRef]

Maklan, Stan, and Philipp Klaus. 2011. Customer Experience: Are We Measuring the Right Things? International Journal of Market Research 53: 771-72. [CrossRef]

Masterman, Emma H., and Guy Wood, eds. 2008. Event Marketing: Measuring an Experience? Venice: International Marketing Trends Congress.

McEachern, Morven G., Gary Warnaby, and Caroline Moraes. 2021. The Role of Community-Led Food Retailers in Enabling Urban Resilience. Sustainability 13: 7563. [CrossRef]

Moise, Daniel, Georgescu Bogdan, and Daniel Zgură. 2012. The Use of Event Marketing Management Strategies. Procedia-Social and Behavioral Sciences 46: 5409-13.

Mostafa, Rania B., and Tamara Kasamani. 2021. Brand experience and brand loyalty: Is it a matter of emotions? Asia Pacific Journal of Marketing and Logistics 33: 1033-51. [CrossRef]

Nguyen, Bang, and Lyndon Simkin. 2017. The Internet of Things (IoT) and marketing: The state of play, future trends and the implications for marketing. Journal of Marketing Management 33: 1-6. [CrossRef]

Nono, Wibisono, and Eddy Syah Yahya. 2019. The role of experiential marketing towards satisfaction and re-intention to visit a tourist destination. Journal of Tourism \& Sports Management (JTSM) 1: 1-14.

O'Connor, Cliodhna, and Helene Joffe. 2020. Intercoder Reliability in Qualitative Research: Debates and Practical Guidelines. International Journal of Qualitative Methods 19: 160940691989922. [CrossRef] 
Österle, Benjamin, Marc M. Kuhn, and Jörg Henseler. 2018. Brand worlds: Introducing experiential marketing to B2B branding. Industrial Marketing Management 72: 71-98. [CrossRef]

Öztürk, Resul. 2015. Exploring the Relationships between Experiential Marketing, Customer Satisfaction and Customer Loyalty: An Empirical Examination in Konya. International Journal of Economics and Management Engineering 9: 2817-20.

Pine, B. Joseph, II, and James H. Gilmore. 1998. Welcome to experience economy. Harvard Business Review 76: 97-105.

Rather, Raouf Ahmad. 2020. Customer experience and engagement in tourism destinations: The experiential marketing perspective. Journal of Travel \& Tourism Marketing 37: 15-32.

Rèklaitis, Kęstutis, and Lina Pilelienè. 2019. Principle Differences between B2B and B2C Marketing Communication Processes. Management of Organizations: Systematic Research 81: 73-86. [CrossRef]

Rust, Roland T. 2020. The future of marketing. International Journal of Research in Marketing 37: 15-26. [CrossRef]

Schmitt, Bernd H. 1999a. Experiential Marketing: How to Get Customer to Sense, Feel, Think, Act, Relate to Your Company and Brands. New York: Free Press.

Schmitt, Bernd. 1999b. Experiential Marketing. Journal of Marketing Management 15: 53-67. [CrossRef]

Schmitt, Bernd, and Lia Zarantonello. 2013. Consumer Experience and Experiential Marketing: A Critical Review. In Review of Marketing Research. Edited by Naresh K. Malhotra. Bingley: Emerald Group Publishing Limited, pp. 25-61.

Srinivasan, Srini R., and Rajesh Kumar Srivastava. 2010. Creating the futuristic retail experience through experiential marketing: Is it possible? An exploratory study. Journal of Retail \& Leisure Property 9: 193-99.

Suchánek, Petr, and Maria Králová. 2018. Customer satisfaction and different evaluation of it by companies. Economic ResearchEkonomska Istraživanja 31: 1330-50. [CrossRef]

Tsai, Shu-pei. 2005. Integrated marketing as management of holistic consumer experience. Business Horizons 48: 431-41. [CrossRef]

Tsaur, Sheng-Hshiung, Yi-Ti Chiu, and Chih-Hung Wang. 2007. The Visitors Behavioral Consequences of Experiential Marketing. Journal of Travel E Tourism Marketing 21: 47-64.

Verma, Sanjeev, Rohit Sharma, Subhamay Deb, and Debojit Maitra. 2021. Artificial intelligence in marketing: Systematic review and future research direction. International Journal of Information Management Data Insights 1: 100002. [CrossRef]

Wiedmann, Klaus-Peter, Franziska Labenz, Janina Haase, and Nadine Hennigs. 2018. The power of experiential marketing: Exploring the causal relationships among multisensory marketing, brand experience, customer perceived value and brand strength. Journal of Brand Management 25: 101-18. [CrossRef]

Williams, Michael, and Tami Moser. 2019. The Art of Coding and Thematic Exploration in Qualitative Research. International Management Review 15: 45-55.

Yazıcı, Tuba, Settar Koçak, and Irmak Hürmeriç Altunsöz. 2017. Examining the effect of experiential marketing on behavioral intentions in a festival with a specific sport event. European Sport Management Quarterly 17: 171-92. [CrossRef]

Yeh, Tsu-Ming, Shun-Hsing Chen, and Tsen-Fei Chen. 2019. The Relationships among Experiential Marketing, Service Innovation, and Customer Satisfaction-A Case Study of Tourism Factories in Taiwan. Sustainability 11: 1041. [CrossRef] 